\title{
Determination of antioxidants in two medicinally important plants, Haloxylon griffithii and Convolvulus leiocalycinus, of Balochistan
}

\author{
Abdul Baqi ${ }^{*}$, Samiullah ${ }^{1}$, Rasool Bakhsh Tareen ${ }^{2}$, Anum Mengal $^{1}$, \\ Naqeebullah Khan ${ }^{1}$, Farida Behlil ${ }^{3}$, Abdul Kabir Khan Achakzai ${ }^{2}$, \\ Muhammad Anwer ${ }^{4}$, Attiq-Ur-Rehman ${ }^{1}$, Mohammad Faheem ${ }^{1}$ \\ 1. Department of Chemistry, University of Balochistan, Quetta 87300-Pakistan \\ 2. Department of Botany, University of Balochistan, Quetta 87300-Pakistan \\ 3. Department of Chemistry, SBK Women University, Quetta 87300-Pakistan \\ 4. Institute of Biochemistry, University of Balochistan, Quetta 87300-Pakistan \\ *Corresponding author's email: abdulbaqi.achakzai@gmail.com \\ Citation
}

Abdul Baqi, Samiullah, Rasool Bakhsh Tareen, Anum Mengal, Naqeebullah Khan, Farida Behlil, Abdul Kabir Khan Achakzai, Muhammad Anwer, Attiq-Ur-Rehman, Mohammad Faheem. Determination of Antioxidants in two medicinally important plants, Haloxylon griffithii and Convolvulus leiocalycinus, of Balochistan . Pure and Applied Biology. Vol. 7, Issue 1, pp296-308. http://dx.doi.org/10.19045/bspab.2018.70036

Received: 20/12/2017 Revised: 12/02/2018

Accepted: 20/02/2018

Online First: 26/02/2018

\section{Abstract}

Determination of antioxidant activity of the two-endemic plants of northern Balochistan Haloxylon griffithii of Chenopodiaceae family and Convolvulus leiocalycinus of Convolvulaceae family is described for the first time in this document. Chemical composition of both the plants was determined by means of well-established chemical tests and modern spectroscopic techniques. Extracts were obtained from both the plants with the help of methanol and the extracts were tested for the measurement of antioxidant activity. In addition, antioxidant potentials were determined spectrophotometrically through the DPPH assay, Ferric ion $\left(\mathrm{Fe}^{+3}\right)$ reducing antioxidant power assay, Ferric $\left(\mathrm{Fe}^{+3}\right)$ reducing antioxidant potential (FRAP) assay and total antioxidant capacity (TAC) of the phosphomolybdenum assay. The potency of the DPPH assay of $H$. griffithii was $95.03 \%$ and C. leiocalycinus was $97.16 \%$ for the $1.0 \mathrm{mg} / \mathrm{ml}$ concentration. Moreover, the FRAP value of both the extract was $3.549 \mathrm{mg}$ of ascorbic acid/g of $\mathrm{H}$. griffithii extract and $4.774 \mathrm{mg}$ of ascorbic acid/g of $C$. leiocalycinus extract. The total antioxidant capacity is a determination of water-soluble and fat-soluble antioxidants expressed a similar concentration dependent style (in $\mathrm{mg} / \mathrm{g}$ ascorbic acid equivalent). $H$. griffithii and $C$. leiocalycinus have proved to be having high potent antioxidant activity.

Keywords: Antioxidant activity; DPPH; Extractions; FRAP; RP; Spectrophotometer; TAC

Introduction

Pakistan and her flora is rich of medicinal plants owing to its varied climatic change, soil conditions and various ecological territories. Considering the general survey of Pakistan, six thousand types of flowering 
plants present out of which almost 400-600 are medicinally crucial species $[1,2]$. Lots of plants have capacity in curing diseases and can be utilized as natural protector [3].

Plants were used as medicines in the prehistoric human civilization. Previously, Chinese, Indian and North African civilization confirmed the medicinal importance of series of plants while curing different diseases. In $19^{\text {th }}$ century, a breakthrough was made when therapeutics generated the plan to isolate biologically active compounds from analeptic plants. With the help of this, the popular antimalarial drug i-e, quinine was executed by French researchers, Caventou and Pelletier, who showed to be innovative in the ground of phyto-remediation [4].

The knowledge about antioxidant potential found in medicinal plants is important due to their medicinal path way. Antioxidant is required anywhere when there is the possibility of oxidation [5].

Oxidation is the process of gaining oxygen, removing of hydrogen, loss of electron and increase in oxidation states. It is one of the significant metabolic course of cells. The body utilizes oxygen and essential particles to generate energy. Oxygen also empowers the immune system combat illness and dangerous constituents. During oxidation, different reactive radicals are created in the shape of free radicals like hydrogen peroxide $\left(\mathrm{H}_{2} \mathrm{O}_{2}\right)$ and alkyl peroxides (ROOR). Furthermore, these free radicals can react with electron plentiful centers in bio molecules such as carbohydrates, DNA and fats. This interruption disturbs the cell function which in turn weakens the immune system. As a result, carcinogenesis, cardiovascular and inflammatory ailments may be developed [6]. Antioxidants are the bits which can scavenge such oxidants and stop tissue impairment [7]. They also diminish oxidative injuries to biomolecules by moderating the influence of active oxidants [8].

In short, antioxidants can save or inhibit oxidation by reducing localized oxygen quantity so that occurrence of oxidation is less. They prevent initiation process to scavenge free radicals which are able of directly capturing hydrogen from molecules. They also assist in binding transition metal ion catalysts like $\mathrm{Cu}$ and $\mathrm{Fe}$ to avoid formation of opening free radicals. Furthermore, they are involved in decaying peroxides to obstruct their conversion to brisker and initiating radical constituents. They react with chain propagating radicals like the peroxyl and alkoxyl radicals to impair nonstop hydrogen pulling from side chain of fatty acid [9].

The addition of both natural and synthetic antioxidants in the food cause the prevention of detrimental decline. For instance, synthetic antioxidants such as butylated hydroxyanisole (BHA) and butylated hydroxytoluene (BHT) are utilized as food preservatives despite the question of their security and toxicity $[10,11]$. Hence, the need for new and reliable antioxidant agents is still of great significance [12]. In addition, various medical innovative and epidemiological investigations have unearthed acontrary gathering among the utilization of vegetables, fruits and illnesses like flagging of the immune pathway, cardiovascular, cancer and illnesses of inflammation [13]. In fact, medicinal plants, vegetables and fruits are sought to be the greatest sources of antioxidants [14]. Therefore, therapeutic power of such plants is thus associated to their antioxidant influence $[15,16]$. The major antioxidants sought in plants are phenolics and flavonoids [17].

The antioxidants separated from medicinal plants have great potential and activity compared to those present in vegetables and fruits [18]. 
So, plant extracts are examined for their antioxidant abilities and to separate the antioxidants that are more potent and less injurious to living organisms [19].

As a result, this is of gigantic significance to the public, medical experts, dietary specialists and nutritional investigators to identify the antioxidant potential of various edible along with medicinal plants.

Different techniques are used to determine the antioxidant power of plant extracts, both in vivo and in vitro. Considering the reaction mechanism, such assays are categorized into two wide range: Hydrogen atom transfer assay (HAT) like restraint of induced LDL auto-oxidation, oxygen radical absorbance capacity (ORAC), total radical trapping antioxidant parameter (TRAP), crocin bleaching assays and electron transfer assay (ETA) that includes the TPC assay by the Folin reagent, Trolox equivalence antioxidant capacity (TEAC), ferric ion $\left(\mathrm{Fe}^{3+}\right)$ reducing antioxidant power (FRAP), "total antioxidant potential" assay where $\mathrm{Cu}$ (II) complex captures electrons, and DPPH assay. Each individual method determines the antioxidant activity under specific situations applied in that system, thus it is not true to infer the knowledge acquired as indicators of "total antioxidant activity". Basically, antioxidant activity of the plant extract mainly depends on the extraction process and conditions like solvent and temperature. In most cases, the solvent used was ethanol, methanol, ethyl acetate, acetone and boiling water. Most crucial to notice is that the herbal medicines used at homes under conditions which are totally different from the conditions used in research laboratories, hence, the antioxidant power will be different in both [19-21].

$H$. griffithii is included in the Chenopodiaceae family, known as Cat tail family. It comprises of one hundred genera and twelve hundred species [22]. Its other kinds are weedy and breed in useless and unproductive soil. The Haloxylon class includes thirteen species cultivating in the dry regions of the North-African and Arabian deserts, and South-West Asia. The members in the Haloxylon genus are vegetations or small trees [23]. In this genus about five species are sought in Pakistan out ofsix species in Central Asia [24]. However, the $H$. griffithii is distributed in the forests of Balochistan as well ascommonly found in the territories of Wali Tangi, Hanna Urak and Spinni road near Quetta. The following (Figure $1 \& 2$ ) show the stem, leaves, flowers and roots of $H$. griffithii collected from Hanna valley and Spinni road.

C. leiocalycinus is included in the Convolvulaceae family. However, Convolvulus is a genus consisting of about two hundred to two hundred and fifty species of flowering plants in the bindweed family Convolvulaceae. But, C. leiocalycinus is distributed along the common upper Balochistan on open rocky ground and stony slopes at $1500 \mathrm{~m}$. It can also be found in hill of Hanna lake along in Ziarat, Brori hill near Quetta. C. leiocalycinus has glabrous ovary, stile 8-9 times the length of stigma and having smaller leaf size. The following (Figure $3 \& 4$ ) showed the stem, leaves and roots of $C$. leiocalycinus collected from the hilly areas of Hanna valley. 
Baqi et al.

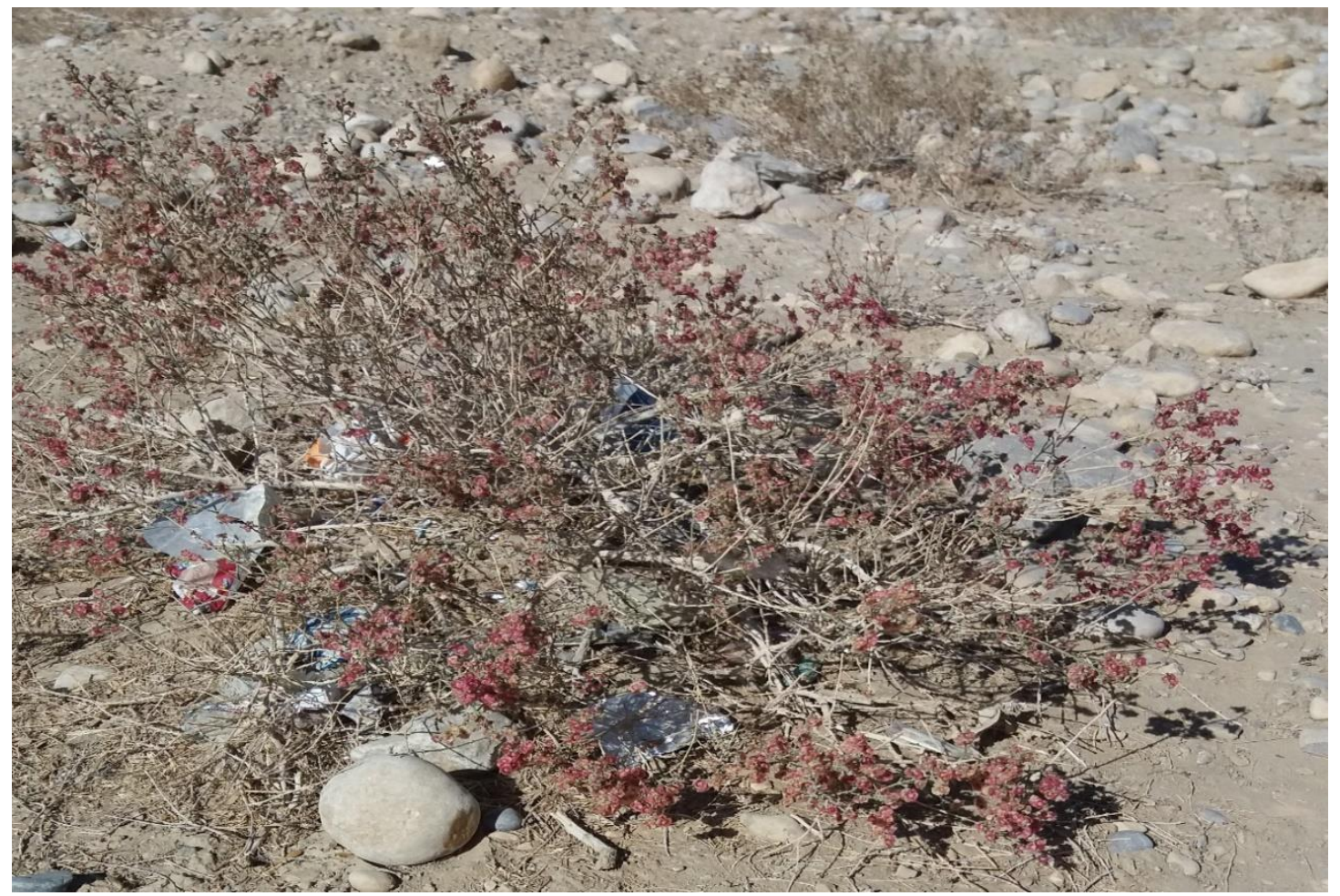

Figure 1. H. griffithii grown in plain areas of Hanna valley

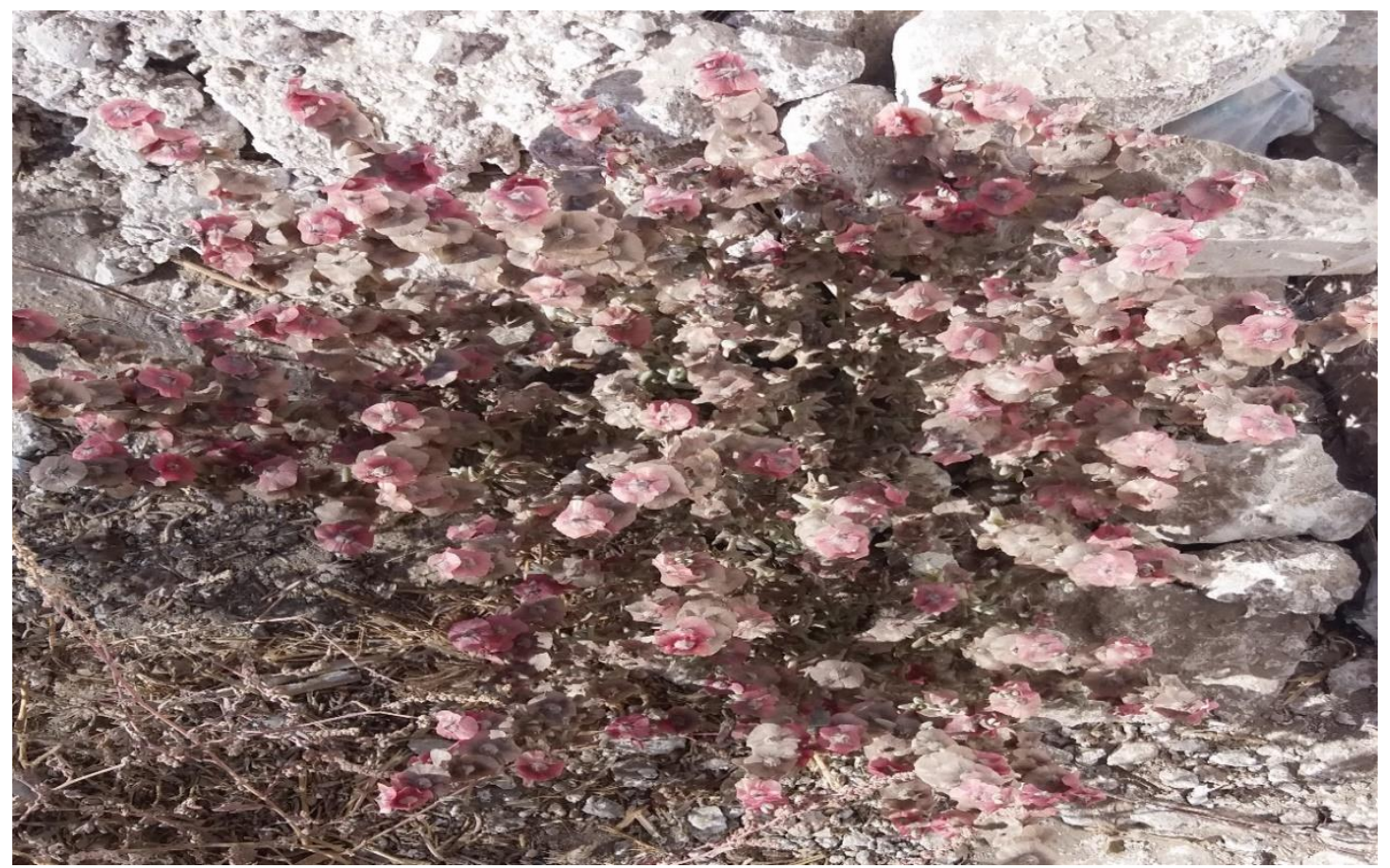

Figure 2. H. griffithii grown in plain areas of Spinni road 


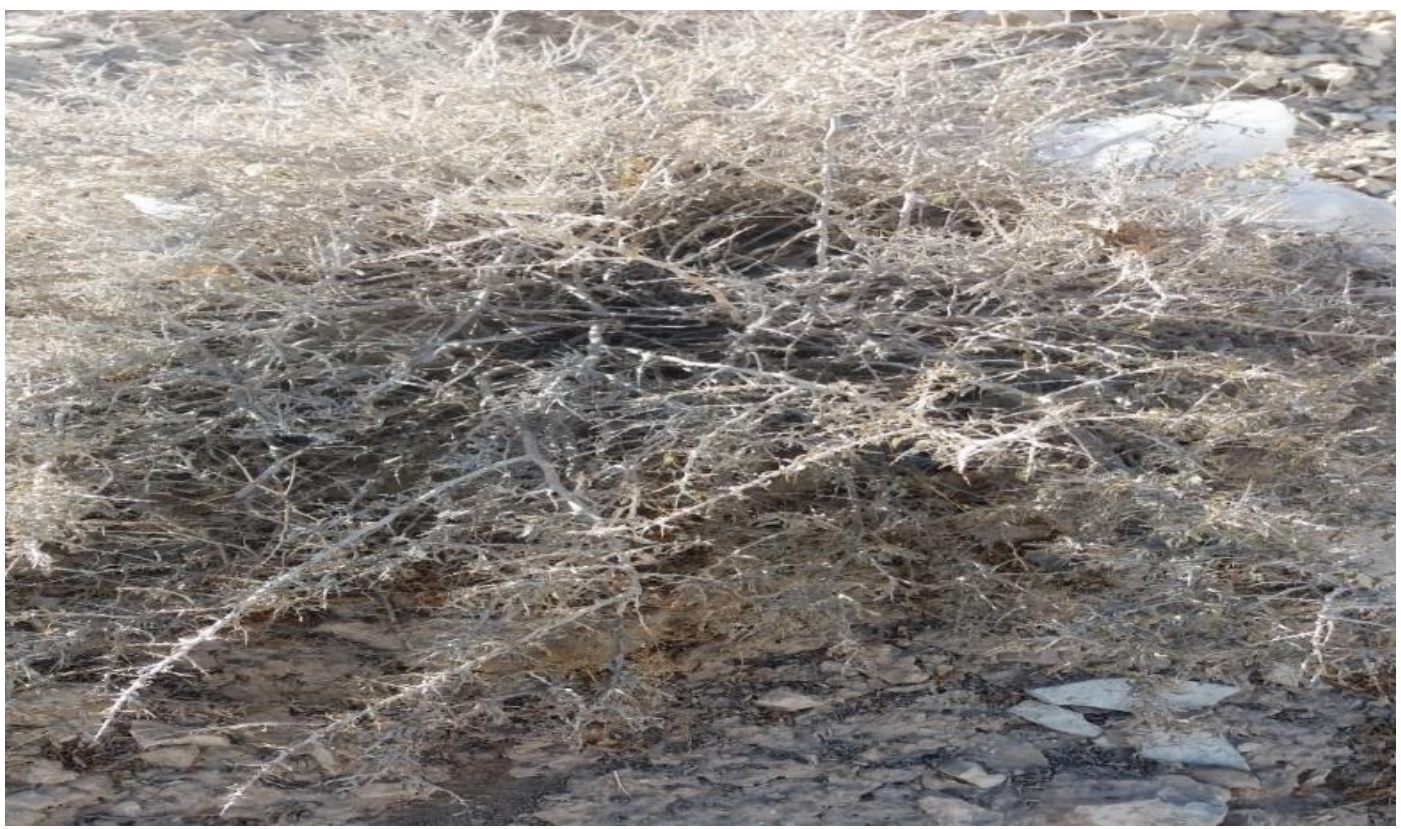

Figure 3. C. leiocalycinus grown in the hilly areas of Hanna Lake

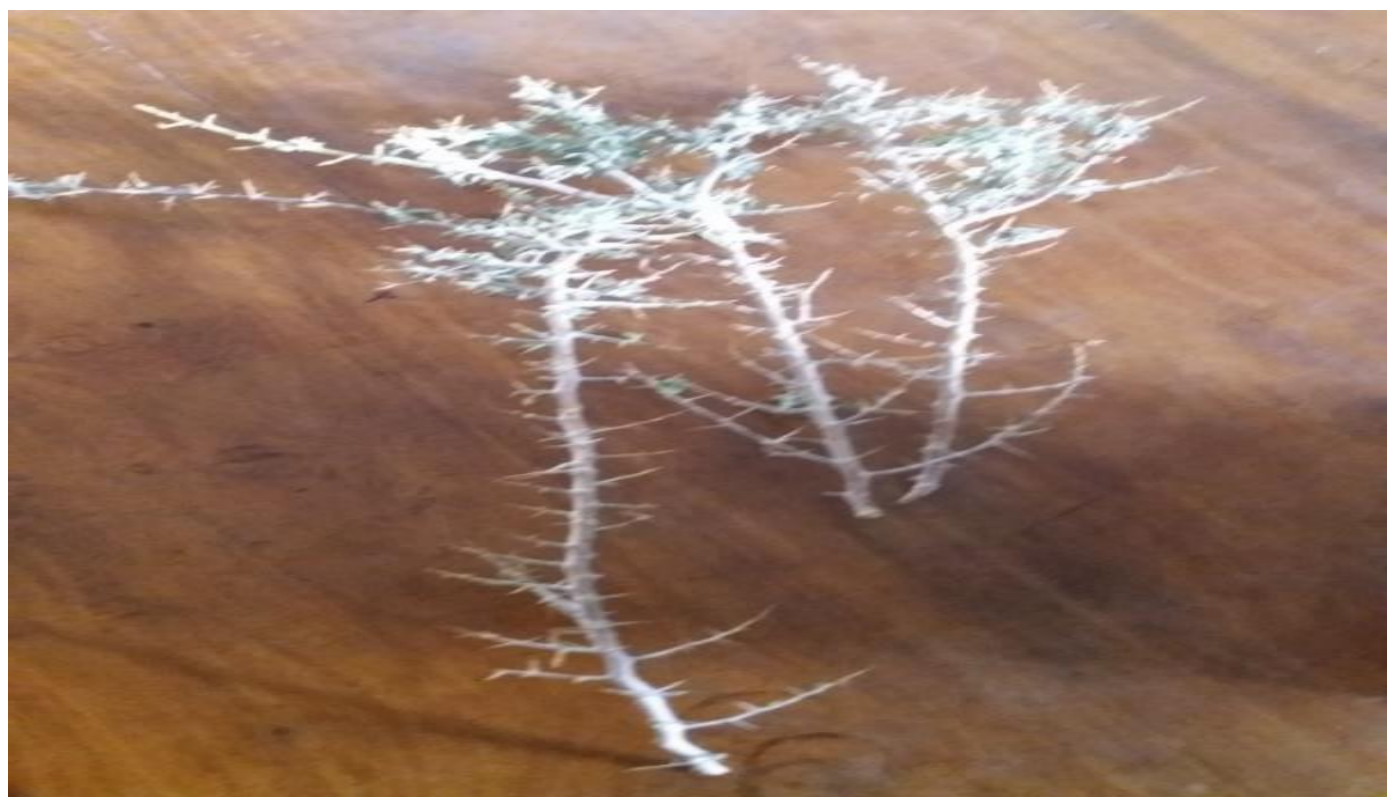

Figure 4. C. leiocalycinus

Extraction can be accomplished by performing different techniques like maceration, digestion, soxhlet extraction, percolation, sonication, decoction and supercritical fluid extraction [25]. Considering antioxidants, no work has been performed yet on these medicinal plants. This study will be the first examination to describe the antioxidant potential of these plants species.

The fundamental theme of this study is to determine antioxidant activity with the help of various assays of $H$. griffithii of Chenopodiaceae family and $C$. leiocalycinus 
of Convolvulaceae family to comprehend the capability of these endemic plants as a rich means of antioxidants. The antioxidant potential of the plant extracts was examined with the help of radical scavenging activities and reducing powers and connection among these parameters were also studied. For the recent work, two plant species were chosen. The choice of such plants was based on the examination that these have been utilized by native healers extremely for the cure of various diseases. These plants were exposed for antioxidant capacity to determine their clandestine antioxidant power.

\section{Materials and methods \\ Reagents and Solutions}

The whole apparatus used in antioxidant process like all plastics and glassware were thoroughly washed with cleaner and further cleaned with deionized water. They were all placed in dry and clean place. The whole reagents utilized in were of analytical grade obtained from Merck.

\section{Plant Material}

The plant samples were collected from Hanna valley, north of Quetta, and Spinni road and the plant species were recognized by Professor Rasool Bakhsh Tareen.

\section{Solvent Extraction}

The leaves, stems and roots of both plants were dried under shade, they were cut and grounded to a powder form. The coarse portion was isolated from the powder ones and kept them for grinding once more. The fine powdered portion weighed $5 \mathrm{~kg}$ was dipped in methanol $15 \mathrm{~L}$ for seven days with occasional stirring and shaking. Moreover, the mixture was filtered through filter paper (Whatman No.1). The process was repeated three times till no change in color was observed. The filtrate so obtained was evaporated on a rotary evaporator under reduced pressure at $35^{\circ} \mathrm{C}$ to acquire a partially dried crude methanolic extract (CME). This crude methanolic extract was shifted to pre-weight china dish and let it to evaporate in a cool, dark and dry place. After thorough evaporation, the residue was weighed $300 \mathrm{~g}$. The crude methanolic extract was used for the examination of antioxidant potential of $H$. griffithii and $C$. leiocalycinus. DPPH radical scavenging capacity assay The 1,1-diphenyl-2-picrylhydrazyl (DPPH) plays a crucial role in the study of scavenging of free radicals. This radical scavenging assay was examined through basic techniques arranged by Barku, Naeema and Yan [26-28]. The DPPH assay consists of the following method in the determination of antioxidants in the crude methanolic extract (CME). Different concentration of solutions of CME like $0.05,0.2,0.4,0.6,0.8$ and $1.0 \mathrm{mg} / \mathrm{ml}$ were prepared in methanol. Newly prepared $1 \mathrm{ml}$ DPPH solution $(0.1 \mathrm{mM}=3.943 \mathrm{mg} / 100$ $\mathrm{ml}$ in methanol) was added with $2 \mathrm{ml}$ of all the samples $0.05,0.2,0.4,0.6,0.8$ and 1.0 $\mathrm{mg} / \mathrm{ml}$. Considering the positive control in the DPPH method, similar concentrations of ascorbic acid solutions 0.05 to $1.0 \mathrm{mg} / \mathrm{ml}$ were also arranged in same solvent. As the DPPH solution to the test samples were added, they were put in the dark for about 30 minutes. The absorbance was taken at 517 nm by means of UV-VIS spectrophotometer (UV-VIS 1700, Shimadzu). For calculating the absorbance of the control, methanol was used instead of the plant extract such as $1 \mathrm{ml}$ DPPH $(0.1 \mathrm{mM}$ solution $+2 \mathrm{ml}$ methanol $)$ to form the similar samples as was taken in the case of test solutions. For blank, methanol was used instead of DPPH. To measure the DPPH radical scavenging ability, the blank's absorbance was deducted from the absorbance of the reacting samples and indicated as the percent drop off in the absorbance of the reacting species than that of the control. The immense radical catching ability of the CME of $H$. griffithii and $C$. leiocalycinus is expressed by the declined absorbance of the reacting mixture.

The given equation was used to determine the capturing DPPH free radical by CME. 
\%age of radical capturing activity $=$ $\left(\mathrm{Abs}_{\text {(control) }}-\mathrm{Abs}_{\text {(sample) })}\right) / \mathrm{Abs}_{\text {(control) }} \times 100 \%$

As,

$\mathrm{Abs}_{(\text {control })}=$ Absorbance of DPPH solution $\mathrm{Abs}_{(\text {sample })}=$ Absorbance of the crude methanolic extract and vitamin $\mathrm{C}$ (ascorbic acid) solutions plus DPPH. The DPPH radical catching ability of the $\mathrm{CME}$ in contrast with vitamin $\mathrm{C}$ (ascorbic acid) is shown in (Figure 5).

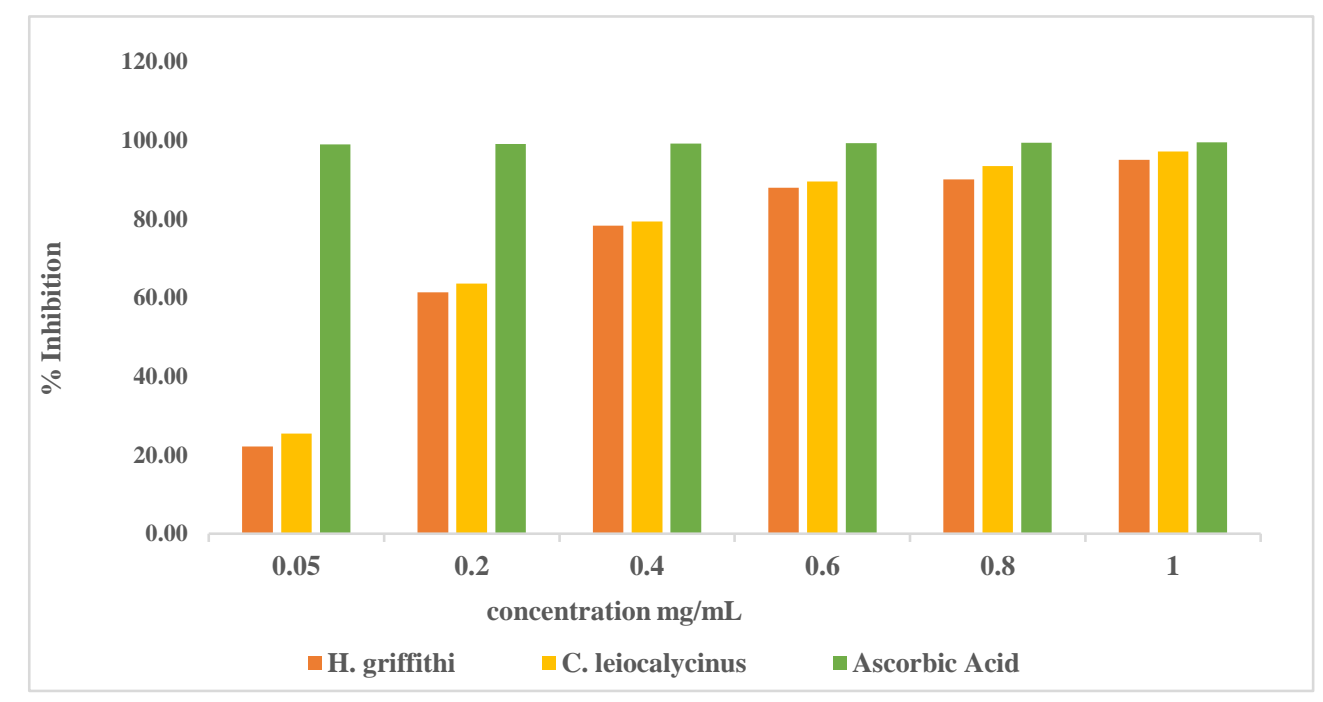

Figure 5. Bar graph indicating comparison of \% DPPH radical scavenging activity between various concentrations of extract and ascorbic acid

\section{Ferric ion $\left(\mathrm{Fe}^{+3}\right)$ reducing antioxidant power assay}

The ferric reducing antioxidant potential of the CME of $H$. griffithii and C. leiocalycinus was measured by the method presented by Saeed et al with few modifications [28]. Stock solutions were made by mixing $10 \mathrm{mg}$ of extract of both plants with $10 \mathrm{ml}$ of extraction solvent. Moreover, different concentrations of the extract were made in the range of $0.05,0.2$ to $1.0 \mathrm{mg} / \mathrm{ml}$ in methanol. The various concentration of crude extract was combined with phosphate buffer (2.5ml, 0.2M, pH 6.60) and 1\% Potassium ferricyanide $\quad\left[\mathrm{K}_{3} \mathrm{Fe}(\mathrm{CN})_{6}\right] \quad(2.5 \mathrm{ml})$. In addition, the samples were incubated for 20 minutes in a water bath at $50-51{ }^{\circ} \mathrm{C}$. After incubation, $2.5 \mathrm{ml}$ of $10-11 \%$ trichloroacetic acid $\left(\mathrm{Cl}_{3} \mathrm{CCOOH}\right)$ was added in the mixture followed by centrifugation for 15 minutes at $1500 \mathrm{rpm}$ (EBA 20, Hettich Zentrifugen). Later, the supernatant of the solution was collected and added an equal volume of deionized water and $0.1 \mathrm{ml}$ of $0.1 \%$ ferric chloride $\left(\mathrm{FeCl}_{3}\right)$ solution. The absorbance was taken via UV-Vis spectrophotometer (UV-VIS 1700, Shimadzu) at $700 \mathrm{~nm}$. For the formation of control, same technique was used removing samples. Ascorbic acid was employed as standard antioxidant. The enhancement in the absorbance of reaction samples indicates the enhancement of reducing power of the $\mathrm{CME}$ of $H$. griffithii and $C$. leiocalycinus. The ascended absorbance is shown in (Figure 6). 


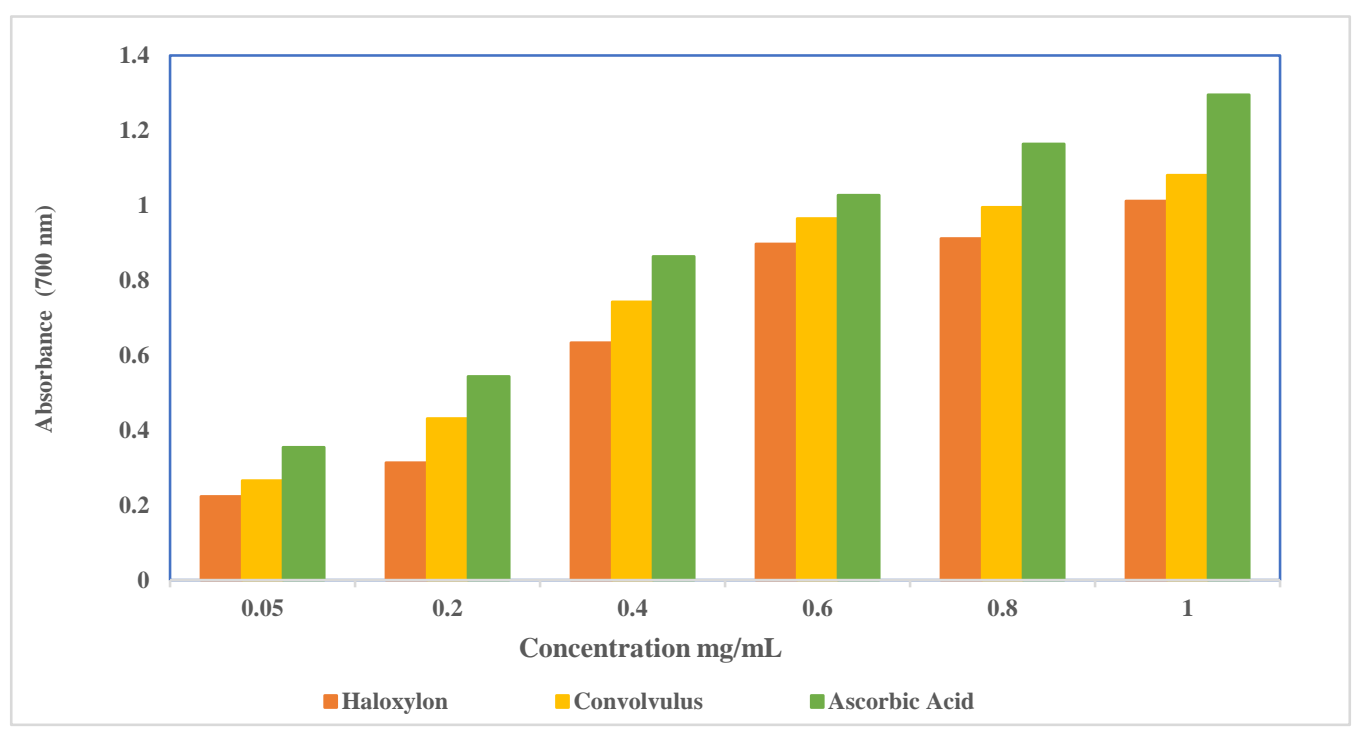

Figure 6. Bar graph expressing the contrast of Ferrum reducing power between various concentrations of the extract and ascorbic acid

\section{Ferric $\left(\mathrm{Fe}^{+3}\right)$ reducing antioxidant potential (FRAP) assay}

The ferric ion reduction potential of crude methanolic extract of $H$. griffithii and $C$. leiocalycinus was determined through an advanced technique of the FRAP assay [29]. The main aim of this procedure is the reduction of ferric ions $\left(\mathrm{Fe}^{+3}\right)$ to ferrous ions $\left(\mathrm{Fe}^{+2}\right)$ exist as central metal atoms in the tripyridyltriazine complex, at a low $\mathrm{pH}$. The reduction is shown clearly through a color change of a colorless $\mathrm{Fe}^{+3}$ complex to a blue $\mathrm{Fe}^{+2}$ complex. The CME of both plants donate the electron for reduction showing the presence of such species. The absorbance of electrons by the Ferric complex is checked by computing the change in UV-VIS absorbance at $593 \mathrm{~nm}$. The FRAP reagent was made by mixing $10 \mathrm{ml}$ of $23 \mathrm{mM}$ acetate buffer $(\mathrm{pH}$ $3.65)$ to $1 \mathrm{ml}$ of $10 \mathrm{mM}$ tripyridyltriazine (TPTZ) in $40 \mathrm{mM} \mathrm{HCl}$ followed by the addition of $1 \mathrm{ml}$ of $20 \mathrm{mM} \mathrm{FeCl}_{3}$ in the ratio of 10:1:1 (v/v/v). Several concentrations of ascorbic acid were made to get a standard curve. Whole of the solutions were freshly made and used. A volume of $0.5 \mathrm{ml}$ of $\mathrm{CME}$ solution at various concentration $(0.05,0.2$ to $1.0 \mathrm{mg} / \mathrm{ml}$ ) and one milliliter of distilled water were mixed to $2 \mathrm{ml}$ of FRAP reagent. After this, the reaction tubeswere incubated for 30 minutes at $37{ }^{\circ} \mathrm{C}$. The UV-VIS absorbance (UV-VIS 1700, Shimadzu) of the test samples was measured at $593 \mathrm{~nm}$. The same method was revised again with standard solution of ascorbic acid as well to achieve the data for calibration curve (Figure 7). For blank, acetate buffer was used instead of reagent and noted the reading. The difference between CME absorbance and the blank was measured and further applied to compute the FRAP value. In this assay, the reducing ability of the plant extract was calculated with reference to the reaction signal by ascorbic acid solution. The values of FRAP were measured as $\mathrm{mg}$ of ascorbic acid/g of the CME. 


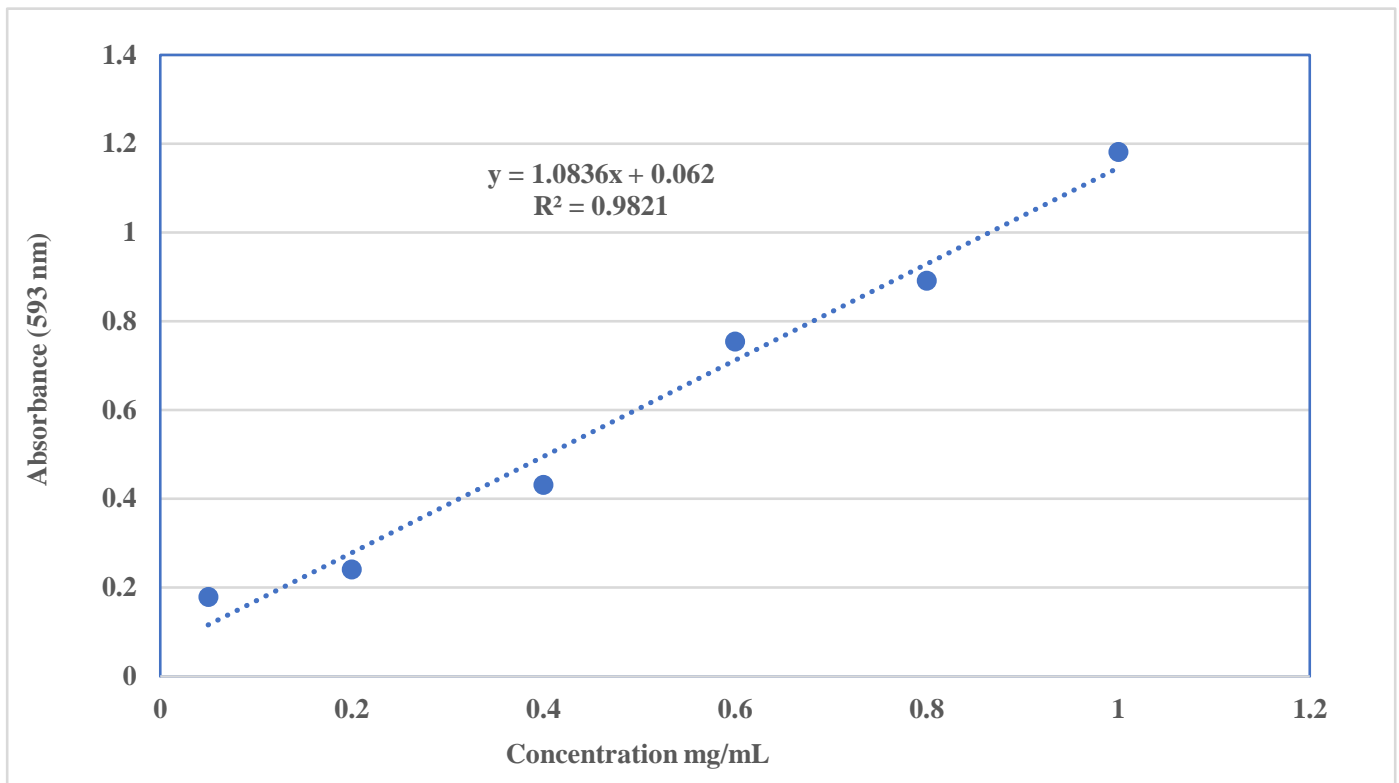

Figure7.Standard calibration curve for the determination of FRAP

Total antioxidant capacity (TAC) (Phosphomolybdenum \{PM\} Assay)

In this method, the entire antioxidant capacity of the crude methanolic extract of $H$. griffithii and $C$. leiocalycinus can be determined. Its fundamental concept is the production of a green phosphomolybdenum [Mo (V)] complex because of the reduction of Mo (VI) to Mo (V) by the CME sample at acidic $\mathrm{pH}$. The quantitative determination of total antioxidant potential can be assessed by the spectrophotometric process [30]. A $0.5 \mathrm{ml}$ extract of the various concentrations $(0.05$, 0.2 to $1.0 \mathrm{mg} / \mathrm{ml}$ ) of both the CME was mixed with $5 \mathrm{ml}$ of molybdate reagent solution $(0.6$ $\mathrm{M} \mathrm{H}_{2} \mathrm{SO}_{4}, 28 \mathrm{mM}$ sodium phosphate and 4 $\mathrm{mM}$ ammonium molybdate mixture). After this, the test samples were closed and kept them for incubation at $95^{\circ} \mathrm{C}$ in water bath for 90 minutes. The test solutions were regularized to room temperature. Later, the UV/VIS spectrophotometers (UV-VIS 1700, Shimadzu) was used to measure the absorbance of the samples at $695 \mathrm{~nm}$ against blank. In the formation of blank, $0.5 \mathrm{ml}$ of methanol was mixed with $5 \mathrm{ml}$ of reagent solution and kept for incubation under similar environment. The antioxidant activity of CME was indicated as $\mathrm{mg}$ equivalent of ascorbic acid for unknown composition of sample. The calibration curve was made by preparing various concentrations of ascorbic acid $(0.05,0.2,0.4,0.6,0.8$ and $1.0 \mathrm{mg} / \mathrm{ml})$ with methanol. The calibration curve is shown in the (Figure 8).

\section{Results and discussion}

The target of this work is to find out the antioxidant potential of the crude methanolic extract of $\mathrm{H}$. griffithii of the Chenopodiaceae family and C. leiocalycinus of Convolvulaceae family with the help of different methods. The antioxidant capacity of both the plants is well expressed and plays a pivotal role in descending coronary illnesses, disorders of age, mental retardation and more significantly their anticancer actions make them important for living organisms [31]. The whole natural antioxidant potential exist in the crude methanolic extract of $H$. griffithii and $C$. leiocalycinus is measured with the help of well established procedures. The routine and broad use of UV/VIS spectrophotometers (UV-VIS 1700, Shimadzu) in the laboratory 
have made them important in the determination of antioxidant in both the plant extracts [32]. These techniques are cheap and quite easy to use which enhances their usefulness [33]. It is a known fact that free radicals are basically highly unstable substances but, they can be stabilized with the help of resonance and conjugation. In this assay, DPPH radical was selected to measure the amount of antioxidants in the CME of $H$. griffithii and C. leiocalycinus. Because of the sustenance of this radical, it can be utilized in simply accessible solvents (water, methanol and ethanol) [34].

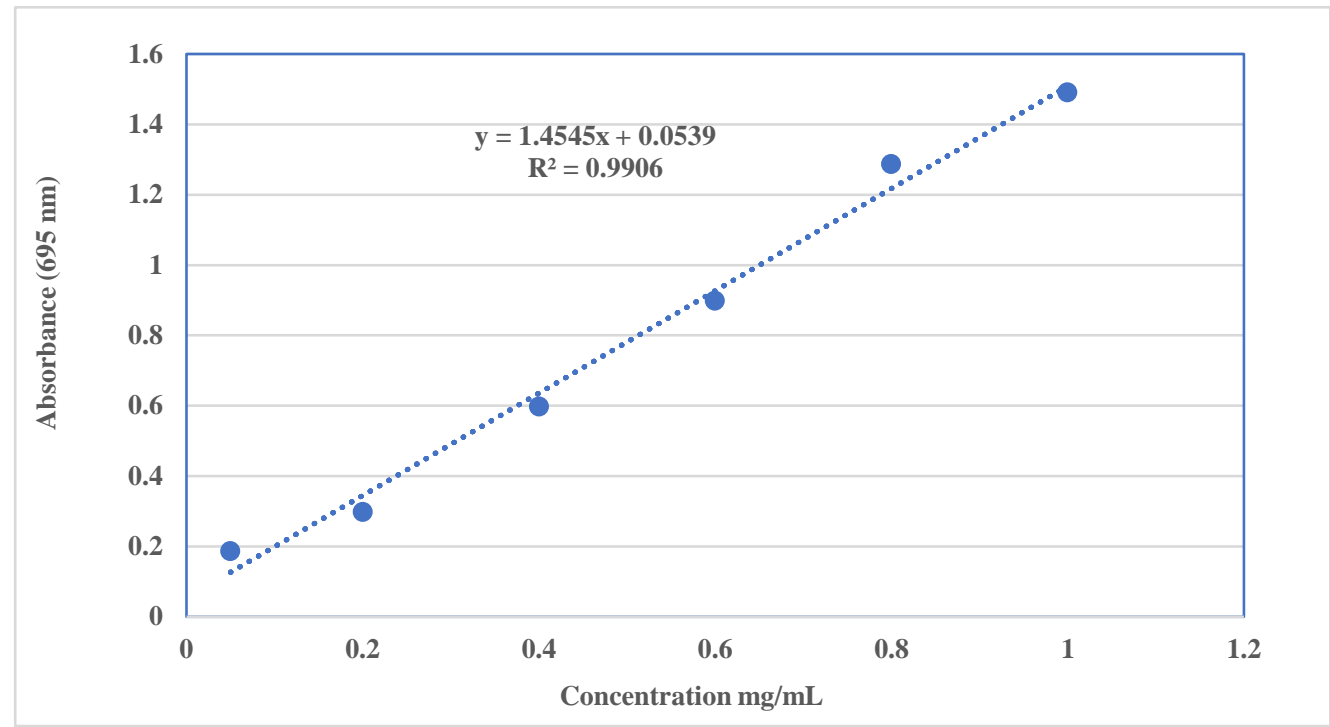

Figure8.Standard calibration curve for the determination of TAC

The electronic transition of such free radical includes the absorbance of photons which have wavelength of $517 \mathrm{~nm}$. The alteration in the location of the absorbance band and color can be readily evaluated as the free radical scavenges a hydrogen atom from the antioxidants exist in the crude methanolic extract. The radical catching ability of the $\mathrm{CME}$ is monitored at all concentrations (Figure 5). In addition, the radical accepting capability of the CME is measured while comparing it to the ascorbic acid, a natural antioxidant. The percentage inhibition of DPPH rises to $95.03 \%$ of $H$. griffithii and $97.16 \%$ of C. leiocalycinus at a concentration of $1.0 \mathrm{mg} / \mathrm{ml}$ of the CME solution expressing that both plants are rich in antioxidants.

The reducing power of both the plant extracts are also measured via reducing $\mathrm{Fe}^{+3}$ ions to $\mathrm{Fe}^{+2}$ ions due to the existence of antioxidants in the crude methanolic extracts as compared to ascorbic acid (Figure 6). This reduction is well assessed due to the conversion ofabsorption maximum of potassium ferricyanide $\left[\mathrm{K}_{3} \mathrm{Fe}(\mathrm{CN})_{6}\right]$, because it is reduced into potassium ferrocyanide $\left[\mathrm{K}_{4} \mathrm{Fe}(\mathrm{CN})_{6}\right]$ due to $\mathrm{CME}$ which is then changed into ferri ferrocyanide $\mathrm{Fe}_{4}\left[\mathrm{Fe}(\mathrm{CN})_{6}\right]_{3}$ in the presence of $\mathrm{FeCl}_{3}$. The enhancement in the absorbance indicates greater amount of antioxidants in the CME of both the plants.

An advanced form of the FRAP assay was utilized to determine the antioxidant amount in the CME of both the plants. In this, a bluish colored ferrous complex $\left(\mathrm{Fe}^{+2}\right.$ tripyridyltriazine) is obtained from the reduction of a colourless ferric complex $\left(\mathrm{Fe}^{+3}\right.$-tripyridyltriazine) with the aid of natural antioxidants present in the CME of both the plants in a process where few protons are available. The reduction is 
suitably examined through calculating the alteration in absorbance at $593 \mathrm{~nm}$. The quantity of natural antioxidants present in the CME is measured from a standard calibration curve (Figure 7).The regression equation for the standard curve of ascorbic acid is: $\mathrm{y}=$ $1.0836 \mathrm{x}+0.062$, where $\mathrm{y}$ is absorbance and $\mathrm{x}$ is the concentration of ascorbic acid. The FRAP technique indicates a concentration of $3.325 \mathrm{mg}$ of ascorbic acid/g of H.griffithii extract and 4.746mgof ascorbic acid/g of $C$. leiocalycinus extract. These amount of antioxidants in $H$. griffithii and $C$. leiocalycinus express that they are rich sources of natural antioxidants.

The result of total antioxidant capacity (TAC) is indicated in (Figure 8). PM assay determines the reduction degree of Mo (VI) to Mo (V). Basically, it is a quantitative technique to find out the reduction reaction rate among antioxidant, oxidant and molybdenum ligand. TAC of the phosphomolybdenum model estimates both water-soluble and fat-soluble antioxidant capability (total antioxidant capacity). It consists in thermally creating auto-oxidation during extended incubation period at larger temperature. Furthermore, it provides a direct evaluation of reducing ability of antioxidant. It is typical from FRAP assay because it sustains irrespective of concentration of free metal ions. Unlike FRAP, it gives a green phosphomolybdenum complex without induction of free metal ions solution. Hence, it exhibits peculiarity among invitro antioxidant assays.

\section{Conclusion}

This research reveals the concentration of antioxidants present in the crude methanolic extract of both the plants by utilizing four well established techniques. $H$. griffithii and C. leiocalycinus contain greater number of antioxidants.

\section{Acknowledgement}

We are thankful to the Department of Chemistry, University of Balochistan for facilitating this work.

\section{Authors' contributions}

Conceived and designed the experiments: A Baqi, Samiullah \& RB Tareen, Performed the experiments: A Baqi, Analyzed the data: A Baqi, Samiullah, N Khan, F Behlil, AU Rehman \& M Faheem, Contributed materials/ analysis/ tools: AKK Achakzai \& M Anwer, Wrote the paper: A Baqi, Samiullah \& RB Tareen \& A Mengal.

\section{References}

1. Nasir E \& Ali SI (1971-91). Flora of West Pakistan. Islamabad, Pakistan. Agric Research Council 1-190.

2. Hamayun M, Khan SA, Iqbal I, Rehman G \& Hayat T (2005). Ethnobotanical profile of Utror and Gabral valleys, district Swat, Pakistan. Ethnobotanical Leaflets (1): 9.

3. Erdemgil FZ, Ilhan S, Korkmaz F, Kaplan C, Mercangöz A, Arfan M \& Ahmad S (2007). Chemical Composition and Biological Activity of the Essential Oil of Perovskia atriplicifolia from Pakistan. Pharmaceutical Biology 45(4): 324-331.

4. Phillipson JD (2001). Phytochemistry and medicinal plants. Phytochemistry 56(3): 237-243.

5. Zhu YZ, Huang SH, Tan BKH, Sun J, Whiteman M \& Zhu YC (2004). Antioxidants in Chinese herbal medicines: a biochemical perspective. Natural Product Reports 21(4): 478-489.

6. Sharma SK \& Singh AP (2012). In vitro antioxidant and free radical scavenging activity of Nardostachys jatamansi DC. Journal of Acupuncture and Meridian Studies 5(3): 112-118.

7. Fitzmaurice SD, Sivamani RK \& Isseroff RR (2011). Antioxidant therapies for wound healing: a clinical guide to currently commercially available products. Skin Pharmacology and Physiology 24(3): 113-126. 
8. Adom KK \& Liu RH (2002). Antioxidant activity of grains. Journal of Agricultural and Food Chemistry 50(21): 6182-6187.

9. Duthie GG (1999). Determination of activity of antioxidants in human subjects. Proceedings of the Nutrition Society 58(4): 1015-1024.

10. Kahl R (1984). Synthetic antioxidants: biochemical actions and interference with radiation, toxic compounds, chemical mutagens and chemical carcinogens. Toxicology 33(3-4): 185228.

11. Pokorný J (2007). Are natural antioxidants better-and safer-than synthetic antioxidants? European Journal of Lipid Science and Technology 109(6): 629-642.

12. Orhan I, Kartal M, Asaker AM, Şenol FS, Yilmaz G \& Şener B (2009). Free radical scavenging properties and phenolic characterization of some edible plants. Food Chemistry 114(1): 276-281.

13. Huang D, Ou B \& Ronald LP (2005). Chemistry Behind Antioxidant Capacity Assay. J Agric and Food Chemistry 53: 1841.

14. Schuler P (1990). Natural antioxidants exploited commercially. Hudson. BJF Elsevier, London, Food Antioxidants 2: 99.

15. Pokornynds J (2010). Antioxidant activity of selected phenols and herbs used in diets for medical conditions. Czech J of Food Sciences 28(4): 317325.

16. Barku VYA, Boahen OY, Ansah OE \& Mensah EF (2013). Antioxidant activity and the estimation of total phenolic and flavonoid contents of the root extract of Amaranthus spinosus. Asian journal of Plant Science and Research 3(1): 69-74.

17. Shetty S, Udupa S \& Udupa L (2008). Evaluation of antioxidant and wound healing effects of alcoholic and aqueous extract of Ocimum sanctum Linn in rats.
Evidence-Based Complementary and Alternative Medicine 5(1): 95-101.

18. Chodak AD, Tarko T \& Rus M (2011). Antioxidant Activity and Total Phenolic Contents of Selected Medicinal Herbs in Poland. Krakaw Poland 122: 30.

19. Chodak AD, Tarko T \& Rus M (2009). Antioxidant activity of selected herbal plants. Herba Polonica 55(4): 65-77.

20. Wojcikowski K, Stevenson L, Leach D, Wohlmuth H \& Gobe G (2007). Antioxidant capacity of 55 medicinal herbs traditionally used to treat the urinary system: a comparison using a sequential three-solvent extraction process. The $J$ of Alternative and Complementary Medicine 13(1): 103110.

21. Yan X, Rana J, Chandra A, Vredeveld D, Ware H, Rebhun J \& Li Y (2008). Medicinal herb extraction strategy-a solvent selection and extraction method study. In Conference Proceeding. Annual Institute of Chemical Engineering 30: 122.

22. Ali SI \& Qaiser M (2001). Flora of Pakistan, Chenopodiaceae Jointly published by Department of Botany, University of Karachi, Karachi, Pakistan \& Missouri Botanical Press: Missouri Botanical Garden, St Louis, Mussouri USA 204: 185.

23. Ali SI, Qaiser M, Freitag H, Hedge IC, Jafri SMH, Kothe-Heinrich G, Omer S \& Uotila P (2001). Flora of Pakistan, Published by Department of Botany, University of Karachi, Karachi, Pakistan 204: 1, 188, 190.

24. Mhaskar KS, Blatter E\& Caius JF (2000). Indian Medicinal plants published by Indian Books centre, Delhi, IndiaI V: 1212-1214.

25. Handa SS, Singh SP, Longo KG \& Rakesh DD (2008). Extraction Technologies for Medicinal and 
Aromatic Plants, Inter $C$ Sci $H$ tech Trieste 1: 21.

26. Barku VYA, Boahen OY, Ansah OE \& Mensah EF (2013). Antioxidant activity and the estimation of total phenolic and flavonoid contents of the root extract of Amaranthus spinosus. Asian $J$ of Plant Science and Research 3(1): 69-74.

27. Williams BW, Cuvelier ME \& Berset CLWT (1995). Use of a free radical method to evaluate antioxidant activity. LWT-Food Science and Technology 28(1): 25-30.

28. Saeed N, Khan MR \& Shabbir M (2012). Antioxidant activity, total phenolic and total flavonoid contents of whole plant extracts Torilis leptophylla L. BMC Complementary and Alternative Medicine 12(1): 221.

29. Shetty S, Udupa S \& Udupa L (2008). Evaluation of antioxidant and wound healing effects of alcoholic and aqueous extract of Ocimum sanctum Linn in rats. Evidence-Based Complementary and Alternative Medicine 5(1): 95-101.

30. Prieto P, Pineda M \& Aguilar M (1999). Spectrophotometric quantitation of antioxidant capacity through the formation of a phosphomolybdenum complex: specific application to the determination of vitamin E. Analytical Biochemistry 269(2): 337-341.

31. Pandith JI (2012). Phytochemical screening of certain plant species of Agra city. Journal of Drug Delivery and Therapeutics 2(4): 135.

32. Khan AM, Qureshi RA, Ullah F, Gilani SA, Nosheen A, Sahreen S \& Murad W (2011). Phytochemical analysis of selected medicinal plants of Margalla Hills and surroundings. J of Medicinal Plants Research 5(25): 6055-6060.

33. Pelozo MIDG, Cardoso MLC \& Mello JCPD (2008). Spectrophotometric determination of tannins and caffeine in preparations from Paullinia cupana var. sorbilis. Brazilian Archives of Biology and Technology 51(3): 447-451.

34. Bueno FG, Machareth MA, Panizzon GP, Lopes GC, Mello JC \& Leite-Mello EV (2012). Development of a UV/Vis spectrophotometric method for analysis of total polyphenols from Caesalpinia peltophoroides Benth. Química Nova 35(4): 822-826. 